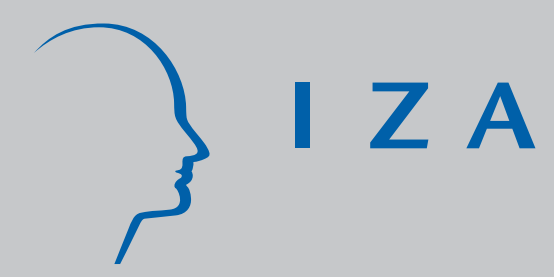

IZA DP No. 1898

Cross-Sectional Heterogeneity in Price-Cost Margins and the Extent of Rent Sharing at the Sector and Firm Level in France

Sabien Dobbelaere

$J$ acques Mairesse

December 2005 


\title{
Cross-Sectional Heterogeneity in Price-Cost Margins and the Extent of Rent Sharing at the Sector and Firm Level in France
}

\author{
Sabien Dobbelaere \\ Ghent University, LICOS K.U. Leuven \\ and IZA Bonn \\ Jacques Mairesse \\ CREST-INSEE, MERIT-Maastricht University \\ and NBER
}

Discussion Paper No. 1898

December 2005

IZA

P.O. Box 7240

53072 Bonn

Germany

Phone: +49-228-3894-0

Fax: +49-228-3894-180

Email: iza@iza.org

Any opinions expressed here are those of the author(s) and not those of the institute. Research disseminated by IZA may include views on policy, but the institute itself takes no institutional policy positions.

The Institute for the Study of Labor (IZA) in Bonn is a local and virtual international research center and a place of communication between science, politics and business. IZA is an independent nonprofit company supported by Deutsche Post World Net. The center is associated with the University of Bonn and offers a stimulating research environment through its research networks, research support, and visitors and doctoral programs. IZA engages in (i) original and internationally competitive research in all fields of labor economics, (ii) development of policy concepts, and (iii) dissemination of research results and concepts to the interested public.

IZA Discussion Papers often represent preliminary work and are circulated to encourage discussion. Citation of such a paper should account for its provisional character. A revised version may be available directly from the author. 
IZA Discussion Paper No. 1898

December 2005

\section{ABSTRACT}

\section{Cross-Sectional Heterogeneity in Price-Cost Margins and the Extent of Rent Sharing at the Sector and Firm Level in France ${ }^{*}$}

This paper studies cross-sectional heterogeneity in price-cost margins and the extent of rent sharing among 48 sectors and 10738 (mainly manufacturing) firms in France. At the sectoral level, the average price-cost mark-up and the average extent of rent sharing amount to 1.701 and 0.368 respectively. Ignoring the occurrence of rent sharing reduces the average pricecost mark-up to 1.500. At the firm level, the average parameters are estimated at 1.814 and 0.558 respectively. Using the Swamy (1970) methodology which corrects the observed heterogeneity for sampling heterogeneity, the corresponding estimates of their robust true dispersion are 0.694 and 0.204 . Excluding the existence of rent sharing brings the firm-level average price-cost mark-up down to 1.491. The corresponding robust true dispersion amounts to 0.493 .

JEL Classification: $\quad$ C23, D21, J50, L13

Keywords: rent sharing, price-cost margins

Corresponding author:

Sabien Dobbelaere

SHERPPA

Faculty of Economics and Business Administration

Ghent University

Hoveniersberg 24

9000 Gent

Belgium

Email: sabien.dobbelaere@UGent.be

\footnotetext{
*We are grateful to Mark Rogers (Oxford University) and participants at the ZEW Conference on the Economics of Innovation and Patenting (Mannheim, 2005) for helpful comments and suggestions. All remaining errors are ours. S. Dobbelaere started the project when she was visiting CREST.
} 


\section{Introduction}

An empirical literature that examines simultaneously imperfections in both the product and the labour market has emerged recently (Bughin, 1996; Crépon et al., 2002; Dobbelaere, 2004; Neven et al., 2002). This paper goes beyond the existing literature, which studies heterogeneity among sectors, as it focuses on heterogeneity in price-cost margins and the extent of rent sharing at the firm level. More specifically, we focus on cross-sectional heterogeneity in product market and labour market imperfections across French (mainly manufacturing) firms. To examine these important issues, we take advantage of a rich panel of French firms over the period 1978-2001. The sample is obtained by merging firm current account and balance sheet data with information on $R \& D$ and innovation (INSEE, SESSI, DEP, CIS 2, CIS 3). Methodologically, we follow Crépon-Desplatz-Mairesse (1999, 2002) and Dobbelaere (2004). By embedding an Efficient Bargaining type model in a microeconomic version of Hall's (1988) framework, we derive a reduced-form equation. Estimating this equation allows the identification of the firm price-cost margin and the extent of rent sharing.

First, we do not take into account potential firm-level heterogeneity and estimate the parameters of interest at the sectoral level. The sectoral average price-cost mark-up and the average extent of rent sharing amount to 1.701 and 0.386 respectively. Ignoring the occurrence of rent sharing reduces the average pricecost mark-up to 1.500 .

Consequently, we take into account firm-level heterogeneity. We analyse whether the observed cross-sectional dispersion in the two parameters is true or whether it is merely a reflection of sampling variability. We estimate the true dispersion or true heterogeneity in the firm price-cost margin and the extent of rent sharing using the Swamy (1970) methodology (i.e., correcting the observed heterogeneity for sampling heterogeneity). Being based on individual firm regression estimates, the Swamy estimates are robust to the possibility of correlated effects (see Mairesse-Griliches, 1990). The estimates of the average price-cost margin and the average extent of rent sharing are respectively 1.814 and 0.558 , while the corresponding estimates of their robust true dispersion are 0.694 and 0.204 , which seems plausible given our prior expectation about a reasonable heterogeneity in both parameters. To investigate whether this heterogeneity is not an artefact of "outliers" and large sampling errors, we perform a cleaning experiment. This experiment confirms our previous conclusions. Excluding the existence of rent sharing brings the firm-level average price-cost mark-up down to 1.491. The corresponding robust true dispersion amounts to 0.493 .

We proceed as follows. Section 2 briefly presents our theoretical framework. In Section 3, we start by estimating the parameters of interest at the sectoral level. Consequently, we provide different estimators and indicators of heterogeneity in the firm price-cost margin and the extent of rent sharing. Section 5 concludes. 


\section{Theoretical Framework}

Theoretically, we rely on a model of Crépon et al. $(1999,2002) .{ }^{1}$ We start from a production function $Q_{i t}=\Theta_{i t} F\left(N_{i t}, M_{i t}, K_{i t}\right)$, where $i$ is a firm index, $t$ a time index, $N$ is labour, $M$ is material input, $K$ is capital and $\Theta_{i t}=A e^{a_{i}+a_{t}+u_{i t}}$ is an index of technical change or "true" total factor productivity. The logarithmic differentiation of the production function gives:

$$
\Delta q_{i t}=\varepsilon_{N_{i t}}^{Q} \Delta n_{i t}+\varepsilon_{M_{i t}}^{Q} \Delta m_{i t}+\varepsilon_{K_{i t}}^{Q} \Delta k_{i t}+\Delta \theta_{i t}
$$

We first assume that firms operate under imperfect competition in the product market and act as price takers in the input markets. Assuming that labour and material input are variable factors, short run profit maximization implies the following two first-order conditions:

$$
\begin{gathered}
\varepsilon_{N_{i t}}^{Q}=\mu_{i t} \alpha_{N_{i t}} \\
\varepsilon_{M_{i t}}^{Q}=\mu_{i t} \alpha_{M_{i t}}
\end{gathered}
$$

where $\alpha_{J_{i t}}=\frac{P_{J_{i t}} J_{i t}}{P_{i t} Q_{i t}}(J=N, M)$ is the share of inputs in total revenue. $\mu_{i t}=\frac{P_{i t}}{C_{Q, i t}}$ refers to the mark-up of price over marginal cost. Assuming constant returns to scale $\left(\varepsilon_{N_{i t}}^{Q}+\varepsilon_{M_{i t}}^{Q}+\varepsilon_{K_{i t}}^{Q}=1\right),{ }^{2}$ the capital elasticity can be expressed as:

$$
\varepsilon_{K_{i t}}^{Q}=1-\mu_{i t} \alpha_{N_{i t}}-\mu_{i t} \alpha_{M_{i t}}
$$

Inserting (2), (3) and (4) in (1) and rearranging terms gives following expression of the Solow Residual $S R_{i t}$ :

$$
\begin{aligned}
& \Delta q_{i t}-\alpha_{N_{i t}} \Delta n_{i t}-\alpha_{M_{i t}} \Delta m_{i t}-\left(1-\alpha_{N_{i t}}-\alpha_{M_{i t}}\right) \Delta k_{i t} \\
= & \left(\mu_{i t}-1\right)\left[\alpha_{N_{i t}}\left(\Delta n_{i t}-\Delta k_{i t}\right)+\alpha_{M_{i t}}\left(\Delta m_{i t}-\Delta k_{i t}\right)\right]+\Delta \theta_{i t} \\
= & \beta_{i t}\left(\Delta q_{i t}-\Delta k_{i t}\right)+\left(1-\beta_{i t}\right) \Delta \theta_{i t}
\end{aligned}
$$

where $\beta_{i t}=\frac{P_{i t}-C_{Q, i t}}{P_{i t}}=\frac{\mu_{i t}-1}{\mu_{i t}}$ is the price-cost margin parameter.

Let us now abstain from the assumption that labour is priced competitively. We assume that the union and the firm are involved in an Efficient Bargaining procedure, with both wages $(w)$ and labour $(N)$ being the subject of agreement.

\footnotetext{
${ }^{1}$ For technical details, see Crépon et al. (1999, 2002).

${ }^{2}$ The asumption of constant returns to scale is motivated by the large problem of identification which arises when price-cost mark-up and scale elasticity parameters are estimated simultaneously.
} 
The union objective is to maximize $U\left(w_{i t}, N_{i t}\right)=N_{i t} w_{i t}+\left(\bar{N}_{i t}-N_{i t}\right) \bar{w}_{i t}$, where $\bar{N}_{i t}$ is union membership $\left(0<N_{i t} \leq \bar{N}_{i t}\right)$ and $\bar{w}_{i t} \leq w_{i t}$ is the alternative wage. The firm objective is to maximize its short-run profit function: $\pi\left(w_{i t}, N_{i t}\right)=R_{i t}-w_{i t} N_{i t}-j_{i t} M_{i t}$. The outcome of the bargaining is the asymmetric generalized Nash solution to:

$\max _{w_{i t}, N_{i t}, M_{i t}}\left\{N_{i t} w_{i t}+\left(\bar{N}_{i t}-N_{i t}\right) \bar{w}_{i t}-\bar{N}_{i t} \bar{w}_{i t}\right\}^{\phi_{i t}}\left\{R_{i t}-w_{i t} N_{i t}-j_{i t} M_{i t}\right\}^{1-\phi_{i t}}$

where $\phi_{i t} \in[0,1]$ represents the bargaining power of the union.

The first-order condition with respect to material input is $R_{M, i t}=j_{i t}$, which directly leads to the corresponding equation (3). Maximization with respect to the wage rate and labour respectively gives the following first-order conditions:

$$
\begin{aligned}
& w_{i t}=\bar{w}_{i t}+\frac{\phi_{i t}}{1-\phi_{i t}}\left[\frac{R_{i t}-w_{i t} N_{i t}-j_{i t} M_{i t}}{N_{i t}}\right] \\
& w_{i t}=R_{N, i t}+\phi_{i t}\left[\frac{R_{i t}-R_{N, i t} N_{i t}-j_{i t} M_{i t}}{N_{i t}}\right]
\end{aligned}
$$

Solving simultaneously (7) and (8), leads to an expression for the contract curve: $R_{N, i t}=\bar{w}_{i t}$, or a modified equation (2):

$$
\varepsilon_{N_{i t}}^{Q}=\mu_{i t}\left(\frac{\bar{w}_{i t} N_{i t}}{P_{i t} Q_{i t}}\right)
$$

Defining $\mu_{i t}$ as $\left[\varepsilon_{Q_{i t}}^{R}\right]^{-1}=\left[\frac{R_{Q_{i t} Q_{i t}}}{R_{i t}}\right]^{-1}$, the marginal revenue of labour can be expressed as $R_{N, i t}=\frac{P_{i t} Q_{N, i t}}{\mu_{i t}}$. Using this expression of $R_{N, i t}$, (8) can be rewritten as $\alpha_{N_{i t}}=\phi_{i t}\left(1-\alpha_{M_{i t}}\right)+\left(1-\phi_{i t}\right) \frac{\varepsilon_{N_{i t}}^{Q}}{\mu_{i t}}$.

Rewriting $\varepsilon_{N_{i t}}^{Q}=\mu_{i t} \alpha_{N_{i t}}+\mu_{i t} \frac{\phi_{i t}}{1-\phi_{i t}}\left(\alpha_{N_{i t}}+\alpha_{M_{i t}}-1\right)$, an extra term shows up in the expression of the Solow Residual: ${ }^{3}$

$$
\begin{aligned}
& \Delta q_{i t}-\alpha_{N_{i t}} \Delta n_{i t}-\alpha_{M_{i t}} \Delta m_{i t}-\left(1-\alpha_{N_{i t}}-\alpha_{M_{i t}}\right) \Delta k_{i t} \\
= & \beta_{i t}\left(\Delta q_{i t}-\Delta k_{i t}\right)+\gamma_{i t}\left(\alpha_{N_{i t}}+\alpha_{M_{i t}}-1\right)\left(\Delta n_{i t}-\Delta k_{i t}\right) \\
& +\left(1-\beta_{i t}\right) \Delta \theta_{i t}
\end{aligned}
$$

where $\beta_{i t}=\frac{\mu_{i t}-1}{\mu_{i t}}$ and $\gamma_{i t}=\frac{\phi_{i t}}{1-\phi_{i t}}$.

\footnotetext{
${ }^{3}$ Note that to accomodate two imperfectly competitive markets, we need at least two variable input factors to identify the model. Going beyond Hall (1988) is hence not possible when starting from a value added specification.
} 
By embedding the Efficient Bargaining model into a microeconomic version of Hall's (1988) framework, the Solow Residual can be decomposed into three components: (1) a factor representing the price-cost margin, (2) a factor reflecting the extent of rent sharing and (3) a technological term. The advantages of the extended approach are twofold: it avoids the problematic computation of the user cost of capital to assess the magnitude of the price-cost mark-up and it avoids the measurement of the alternative wage to estimate the extent of rent sharing.

\section{Cross-sectional heterogeneity in price-cost mar- gins and the extent of rent sharing}

In this section, we first present the data. Second, we do not take into account firm-level heterogeneity and estimate the structural parameters of interest $(\mu$ and $\phi$ ) at the sectoral level. Finally, we investigate potential heterogeneity in price-cost margins and the extent of rent sharing across French (mainly manufacturing) firms. Our main question is whether the observed dispersion is just a reflection of sampling variability or whether it is an indication of real heterogeneity.

\subsection{Data description}

We use an unbalanced panel of French firms over the period 1978-2001. This sample has been constructed by merging accounting information of firms from EAE ("Enquête Annuelle d'Entreprise", "Service des Etudes et Statistiques Industrielles" (SESSI)) with data of Research \& Development collected by DEP ("Ministère de l'Education et de la Recherche"). We only keep firms for which we have at least 12 years of observations, ending up with an unbalanced panel of 10738 firms with the number of observations for each firm varying between 12 and $24 .{ }^{4}$ The R\&D surveys (DEP) provide three R\&D variables: a dichotomous R\&D indicator, total R\&D expenditure and R\&D expenditure on personnel. R\&D firms are identified through the $R \& D$ indicator. We assume that the sample is exhaustive, i.e. a firm which does not report any $R \& D$ expenditure is considered to be a non-R\&D firm. Based on this criterion, we construct two subsamples: the pure non-R\&D firms (10186 firms) and the pure R\&D firms for which we have data on $\mathrm{R} \& \mathrm{D}$ expenditure for at least 12 years $(552$ firms). We use real current production deflated by the two-digit producer price index of the French industrial classification as a proxy for output $(Q)$. Labour $(N)$ refers to the average number of employees in each firm for each year and material input $(M)$ refers to intermediate consumption deflated by the two-digit intermediate consumption price index. The capital stock $(K)$ is measured by

\footnotetext{
${ }^{4}$ Putting the number of firms between brackets and the number of observations between square brackets, the structure of the data is given by: (1357) [12], (1217) [13], (1146) [14], (1347) [15], (4399) [16], (150) [17], (149) [18], (137) [19], (110) [20], (81) [21], (98) [22], (99) [23], (448) [24].
} 
the gross bookvalue of fixed assets. The shares of labour $\left(\alpha_{N}\right)$ and material input $\left(\alpha_{M}\right)$ are constructed by dividing respectively the firm total labour cost and undeflated intermediate consumption by the firm undeflated production and by taking the average of these ratios over adjacent years. Table 1 reports the means, standard deviations and first and third quartiles of our main variables.

\section{$<$ Insert Table 1 about here $>$}

\subsection{Estimation method and results}

Variation in input shares is idiosyncratic and possibly related to variation in hours of work, machinery, capacity utilization (variation in the business cycle). When estimating our parameters of interest, we want to abstract from this possible source of contamination. Consistent with the assumption of constancy of $\mu$ and $\phi$, we therefore also assume constant firm-level input shares. ${ }^{5}$

\subsubsection{Sector-level results}

We estimate the following specification for each sector $j$ :

$$
\begin{aligned}
S R_{i t}= & \Delta q_{i t}-\left(\frac{1}{n_{t}} \sum_{t=1}^{n_{t}} \alpha_{N_{i t}}\right) \Delta n_{i t}-\left(\frac{1}{n_{t}} \sum_{t=1}^{n_{t}} \alpha_{M_{i t}}\right) \Delta m_{i t} \\
& -\left(1-\frac{1}{n_{t}} \sum_{t=1}^{n_{t}} \alpha_{N_{i t}}-\frac{1}{n_{t}} \sum_{t=1}^{n_{t}} \alpha_{M_{i t}}\right) \Delta k_{i t} \\
= & \beta\left(\Delta q_{i t}-\Delta k_{i t}\right)+ \\
& \gamma\left(\frac{1}{n_{t}} \sum_{t=1}^{n_{t}} \alpha_{N_{i t}}+\frac{1}{n_{t}} \sum_{t=1}^{n_{t}} \alpha_{M_{i t}}-1\right)\left(\Delta n_{i t}-\Delta k_{i t}\right)+(1-\beta) \zeta_{i t}
\end{aligned}
$$

where $\beta=\frac{\mu-1}{\mu}, \gamma=\frac{\phi}{1-\phi}$ and $n_{t}$ denotes the number of years within firm $i$. Since transitory productivity shocks might affect changes in factor inputs $(\Delta n$, $\Delta m$ and $\Delta k)$, and since the production price is endogenous to our model, Ordinary Least Squares (OLS) estimates of the reduced-form coefficients and the corresponding structural estimates are likely to be biased and inconsistent. To avoid such biases and to take into account endogeneity problems, we estimate (11) for each sector by the Generalized Method of Moments (GMM) technique. More specifically, we use as instruments the 2- and 3-period lagged values of the growth of the input factors $\Delta n, \Delta m$ and $\Delta k$. The exogeneity of the instruments with respect to the error term is tested by the Sargan test statistic which is distributed as chi-squared. To capture possible unobservable aggregate shocks and productivity shocks common to all firms within sector $j$ in a given year, we include time dummies. Estimation is carried out using the Dynamic

\footnotetext{
${ }^{5}$ An experiment decomposing the variables into a constant and a variable part confirms our choice of constant firm-level input shares.
} 
Panel Data program, which works with the Ox programming language (Doornik et al., 2002).

We decompose the total sample into 48 sectors (46 manufacturing sectors, 1 energy and 1 construction sector) according to the French industrial classification ("Nomenclature économique de synthèse - Niveau 3" [NES 114]). For the sake of comparison, we report the OLS estimates. For all reported GMM results, we can never reject the null hypothesis that the instruments are valid on the basis of the Sargan test. The parameters of interest $\left(\hat{\mu}_{j}\right.$ and $\left.\widehat{\phi}_{j}\right)$ are computed from the two-step estimated values of the reduced-form coefficients $\left(\widehat{\beta}_{j}\right.$ and $\widehat{\gamma}_{j}$ respectively). The standard errors $(\sigma)$ of the estimated parameters are computed using the Delta Method (Woolridge, 2002). ${ }^{6}$

As a benchmark, we first ignore the occurrence of rent sharing. Table A.1 in Appendix shows the sector repartition of the sample and the estimated pricecost mark-up $\left(\hat{\mu}_{j}\right)$ for each sector $j$. Focusing on the GMM results, the ratio of price over marginal cost is significantly larger than one at the $1 \%$ level for all sectors. The estimated price-cost mark-up ranges from 1.265 (Metal products for construction [Sec 18]) to 1.930 (Recuperation [Sec 44]) and the average estimated price-cost mark-up amounts to 1.500. On average, the GMM estimates do not differ significantly from the OLS estimates. When we pool all firms and all sectors, the overall average price-cost mark-up is estimated at 1.301. ${ }^{7}$

The results of estimating (11) for each sector are reported in Table 2. Concentrating on the GMM results, the estimated price-cost mark-up is significantly larger than one at the 1\% level for all sectors and varies from 1.319 (Emission and transmission equipment [Sec 15]) to 2.289 (Recuperation [Sec 44]). For 38 out of 48 sectors, the estimated extent of rent sharing is significantly positive at the $1 \%$ level and ranges from $-0.170^{8}$ (Meat preparations [Sec 1]) to 0.745 (Ferruginous and steam boilers [Sec 19]). The average price-cost mark-up and the average extent of rent sharing amount to 1.701 and 0.386 respectively. The correlation between the two estimated structural parameters is $0.466 .{ }^{9}$ On average, the GMM estimates accord very well with the OLS estimates. Except for 4 sectors for which the estimated extent of rent sharing is not significantly different from zero, we find evidence of price-cost mark-ups being underestimated when imperfection in the labour market is ignored, hence validating the findings of Bughin (1996) and Dobbelaere (2004). The correlation between the estimated price-cost mark-up ignoring the occurrence of rent sharing (Table A.1) and the estimate taking into account labour market imperfections (Table 2) amounts to

${ }^{7}$ Note that we use the 3- and 4-period lagged values of $\Delta n, \Delta m$ and $\Delta k$ to estimate the structural parameters at the overall level since the estimates do not satisfy the Sargan test when using the 2- and 3-period lagged values.

${ }^{8}$ This estimate is however not significantly different from zero.

${ }^{9}$ We also estimated a variant of specification (11) with firm- and time-varying input shares within each sector $j: \widehat{S R}_{i t}=\Delta q_{i t}-\alpha_{N_{i t}} \Delta n_{i t}-\alpha_{M_{i t}} \Delta m_{i t}-\left(1-\alpha_{N_{i t}}-\alpha_{M_{i t}}\right) \Delta k_{i t}=$ $\beta\left(\Delta q_{i t}-\Delta k_{i t}\right)+\gamma\left(\alpha_{N_{i t}}+\alpha_{M_{i t}}-1\right)\left(\Delta n_{i t}-\Delta k_{i t}\right)+(1-\beta) \varsigma_{i t}$. The average price-cost mark-up $\hat{\mu}_{j}$ and the average extent of rent sharing $\hat{\phi}_{j}$ are found to be respectively 1.542 and 0.211. The correlation between the two estimated parameters amounts to 0.504 .
} 
0.777. At the overall level, the price-cost mark-up and the extent of rent sharing are estimated at 1.678 and 0.531 respectively. ${ }^{10}$

$<$ Insert Table 2 about here $>$

\subsubsection{Firm-level results}

We now address the question whether there is real heterogeneity in price-cost mark-ups and the extent of rent sharing at the firm level. For each firm $i$, we estimate the following specification:

$$
\begin{aligned}
S R_{t}= & \Delta q_{t}-\left(\frac{1}{n_{t}} \sum_{t=1}^{n_{t}} \alpha_{N_{t}}\right) \Delta n_{t}-\left(\frac{1}{n_{t}} \sum_{t=1}^{n_{t}} \alpha_{M_{t}}\right) \Delta m_{t} \\
& -\left(1-\frac{1}{n_{t}} \sum_{t=1}^{n_{t}} \alpha_{N_{t}}-\frac{1}{n_{t}} \sum_{t=1}^{n_{t}} \alpha_{M_{t}}\right) \Delta k_{t} \\
= & \beta\left(\Delta q_{t}-\Delta k_{t}\right)+\gamma\left(\frac{1}{n_{t}} \sum_{t=1}^{n_{t}} \alpha_{N_{t}}+\frac{1}{n_{t}} \sum_{t=1}^{n_{t}} \alpha_{M_{t}}-1\right)\left(\Delta n_{t}-\Delta k_{t}\right) \\
& +(1-\beta) \varepsilon_{t}
\end{aligned}
$$

We estimate (12) for each of the 10738 firms by the Two-Stage Least Squares (TSLS) method and use the 2-period lagged values of $\Delta n, \Delta m$ and $\Delta k$ as instruments. ${ }^{11}$ As mentioned above, the number of observations for each firm varies between 12 and 24 .

Consistent with the sectoral analysis, we first present in Table A.2 the OLS and TSLS results of estimating $\widehat{\beta}_{i}$ and $\widehat{\mu}_{i}$ under the assumption that labour is priced competitively. The first row lists the simple averages of the individually estimated reduced-form coefficient $\widehat{\beta}_{i}$ and the derived structural parameter $\hat{\mu}_{i}$. The second row reports the weighted average where the weight is defined as the inverse of the square root of the sampling variance. The median values are given in the third row. Focusing on the TSLS results, the median value of the price-cost mark-up $\hat{\mu}_{i}$ is estimated at 1.370 . Concentrating on the non-robust results, the fourth (sixth) row displays the observed (sampling) variance and the observed (sampling) dispersion. These indicators illustrate the enormous dispersion in the estimated structural parameters and show that the heterogeneity at the firm level is largely magnified by large sampling errors arising from the rather short time series available. To determine the "true" dispersion or heterogeneity in the individual $\hat{\mu}_{i}$ 's, we follow the Swamy (1970) methodology. This method allows us to estimate the variance components of heterogeneity, i.e. the pure sampling variance and the true amount of dispersion. Being based

\footnotetext{
${ }^{10}$ The average price-cost mark-up and the average extent of rent sharing at the overall level are estimated at respectively 1.524 and 0.437 when assuming varying firm-level input shares.

${ }^{11}$ Besides allowing for the possible heterogeneity across firms, we could also focus on the stability of the structural parameters over time. However, relaxing the constancy of $\mu_{i}$ and $\phi_{i}$ in the time dimension would strain our already overextended computational framework.
} 
on individual firm regression estimates, the Swamy estimates are robust to the possibility of correlated effects (see Mairesse-Griliches, 1990). Row 8 lists the Swamy estimates which are computed as the difference between the observed variance of the individually estimated $\hat{\mu}_{i}$ and the mean of the corresponding sampling variance. Due to the large sampling variance, we find zero estimates of true dispersion in the individually estimated reduced-form coefficient $\widehat{\beta}_{i}$ and the derived structural parameter $\widehat{\mu}_{i}$. All the observed variability is either common to all firms, transitory or attributable to sampling variability. Focusing on the OLS estimates, both the observed and the sampling variance of $\widehat{\beta}_{i}$ are much smaller than the corresponding observed and sampling variance of the TSLS estimates. Contrary to the TSLS results, the true dispersion in the individual $\widehat{\beta}_{i}$ 's is estimated at 0.181 .

Table 3 presents the OLS and the TSLS results of estimating (12) in a comprehendible fashion. The median value of the price-cost mark-up $\hat{\mu}_{i}$ and the extent of rent sharing $\hat{\phi}_{i}$ are estimated at 1.614 and 0.775 respectively. At the median level, we find again evidence of price-cost mark-ups being underestimated when labour market imperfection is ignored. ${ }^{12}$ The correlation between the individually estimated $\widehat{\mu}_{i}$ 's and $\widehat{\phi}_{i}$ 's is 0.0004 . Consistent with the results reported in Table A.2, the large sampling variance drives the Swamy estimates of true dispersion in the individually estimated reduced-form coefficients and the derived structural parameters towards zero. As to the OLS results, the Swamy estimates of true dispersion in the reduced-form coefficients are however significantly different from zero. This estimate of $\widehat{\gamma}_{i}$, which amounts to 45 , is however much too large to be a credible indicator of heterogeneity.

To investigate whether the observed heterogeneity is not just an artefact of outliers and large sampling errors, we pursue two approaches towards robustness. One approach concentrates on robust indicators and estimates. ${ }^{13}$ In the other approach, we perform a cleaning experiment, cleaning the full sample on the basis of the sampling variance.

In the fifth row of Table A.2 and Table 3, we compute a robust estimate of the observed variance (dispersion) of respectively $\hat{\mu}_{i}$ and, $\hat{\mu}_{i}$ and $\hat{\phi}_{i}$ from their interquartile range. Focusing on the TSLS results of Table 3, a robust observed estimated dispersion $s d_{r o}$ of 1.411 for $\hat{\mu}_{i}$ and 0.263 for $\hat{\phi}_{i}$ is however still not credible given our prior expectation about a reasonable heterogeneity in both parameters. Row 7 lists the robust sampling variance (dispersion). In row 9 , we report the Swamy estimates of the robust true variance which are now computed by subtracting the median -rather than the mean- of the estimated sampling variance from the robust observed variance of the individually estimated $\hat{\mu}_{i}$

\footnotetext{
${ }^{12}$ At the individual level, the correlation between the estimated price-cost mark-up ignoring the occurence of rent sharing (Table A.2) and the estimate taking into account labour market imperfections (Table 3) amounts to -0.083 . For $60 \%$ of the firms, the lack of explicit consideration of labour market imperfections results in a considerable underestimation of the firm-level price-cost mark-up.

${ }^{13}$ When focusing on robust indicators and estimates, we assume that the individually estimated parameters are normally distributed and the sampling variance is distributed as $\chi^{2}$.
} 
and $\hat{\phi}_{i}$. The estimates of true dispersion of 0.694 for $\hat{\mu}_{i}$ and 0.204 for $\hat{\phi}_{i}$ are good indicators of a credible amount of heterogeneity. ${ }^{14}$ The last row reports the F-statistic for the hypothesis of equality of the parameter estimates across firms. Given the large number of degrees of freedom, all the F-statistics are significant at conventional significance levels (the critical value barely exceeds 1 for our sample size). Hence, contrary to the non-robust results, the hypothesis of homogeneity is clearly rejected. ${ }^{15}$

\section{$<$ Insert Table 3 about here>}

Table 4 displays the TSLS results of the cleaning experiment. The left panel shows the results of estimating the price-cost mark-up only, while the right panel reports the results of estimating both the price-cost mark-up and the extent of rent sharing. We eliminate all firms for which the sampling variance of $\hat{\mu}_{i}\left(\hat{\phi}_{i}\right)$ exceeded the median value, ending up with 5365 firms in the left panel and 2328 firms in the right panel. ${ }^{16}$ Concentrating on our parameters of interest $\left(\hat{\mu}_{i}\right.$ and $\left.\hat{\phi}_{i}\right)$, the main findings can be summarised as follows. First, comparing the non-robust indicators and estimates of the full sample with those of the cleaned sample, we see an enormous reduction in the observed variance which is even larger for the estimated sampling variance in the cleaned sample. As a consequence, we find persistent individual firm differences in the estimated $\hat{\mu}_{i}$ 's and $\hat{\phi}_{i}$ 's. The estimate of true dispersion amounts to 0.232 for $\hat{\mu}_{i}$ (left panel) and, 0.638 for $\hat{\mu}_{i}$ and 0.126 for $\hat{\phi}_{i}$ (right panel). Second, the robust results point to a much smaller but still significant reduction in both the robust observed variance and the robust sampling variance. The estimate of true dispersion is found to be 0.178 for $\hat{\mu}_{i}$ (left panel) and, 0.426 for $\hat{\mu}_{i}$ and 0.122 for $\hat{\phi}_{i}$ (right panel). Finally, the non-robust versus robust results are much more consistent in the cleaned sample compared to the full sample. Both results point to a reasonable degree of heterogeneity in both parameters in the cleaned sample.

\section{$<$ Insert Table 4 about here $>$}

To check whether the observed heterogeneity has a sectoral component, we look at within estimates of heterogeneity. Focusing on the estimates of both $\widehat{\mu}_{i}$ and $\widehat{\phi}_{i}$ in the full sample, we find that sector differences explain only $0.4 \%$

\footnotetext{
${ }^{14}$ Consistent with the sectoral analysis, we also estimated a variant of specification (12) with time-varying input shares within each firm $i, \widetilde{S R} R_{t}=\Delta q_{t}-\alpha_{N_{t}} \Delta n_{t}-\alpha_{M_{t}} \Delta m_{t}-\left(1-\alpha_{N_{t}}-\right.$ $\left.\alpha_{M_{t}}\right) \Delta k_{t}=\beta\left(\Delta q_{t}-\Delta k_{t}\right)+\gamma\left(\alpha_{N_{t}}+\alpha_{M_{t}}-1\right)\left(\Delta n_{t}-\Delta k_{t}\right)+(1-\beta) \varrho_{t}$. The median values are estimated at: $0.430\left(\widehat{\beta}_{i}\right), 1.395\left(\widehat{\mu}_{i}\right), 1.395\left(\widehat{\gamma}_{i}\right)$ and $0.770\left(\widehat{\phi}_{i}\right)$. Focusing on the non-robust results, we find zero estimates of true dispersion. The corresponding Swamy estimates of robust true dispersion are $0.306\left(\widehat{\beta}_{i}\right), 0.559\left(\widehat{\mu}_{i}\right), 1.477\left(\widehat{\gamma}_{i}\right)$ and $0.184\left(\widehat{\phi}_{i}\right)$.

${ }^{15}$ One can question, however, the validity of these F-statistics in such large samples. A more symmetric treatment of the inference problem, advocated by Leamer (1978), would necessitate using a critical value which increases with the number of degrees of freedom.

${ }^{16}$ Starting from the results in the right panel of Table A.2, we eliminated all firms for which the sampling variance of $\widehat{\mu}_{i}$ exceeded 0.198. Similarly, starting from the results in the right panel of Table 3 , we eliminated all firms for wich the sampling variance of $\widehat{\mu}_{i}\left(\widehat{\phi}_{i}\right)$ exceeded 1.508 (0.027).
} 
of the observed variance in $\hat{\mu}_{i}$ and $0.7 \%$ of the observed variance in $\hat{\phi}_{i}$. In the corresponding cleaned sample, the within estimates show that $7.1 \%(15 \%)$ of the observed variance in $\hat{\mu}_{i}\left(\hat{\phi}_{i}\right)$ is accounted for by sector effects. In sum, consistent differences between the 48 sectors in the estimated price-cost mark-up and the estimated extent of rent sharing are small but significant contributors to the estimated firm-specific heterogeneity.

Splitting up the full sample into the R\&D subsample (552 firms) and the nonR\&D subsample (10186 firms), gives the following results. The median values of $\hat{\mu}_{i}$ and $\hat{\phi}_{i}$ are 1.512 and 0.762 for the R\&D subsample and 1.620 and 0.776 for the non-R\&D subsample. In both subsamples, the large sampling variance leads to zero estimates of true dispersion in the individually estimated reducedform coefficients and the derived structural parameters. When focusing on the robust estimates, we find individual firm differences in the $\hat{\mu}_{i}$ 's and the $\hat{\phi}_{i}$ 's in the non-R\&D subsample. The true dispersion is $0.698\left(\hat{\mu}_{i}\right)$ and $0.203\left(\hat{\phi}_{i}\right)$. In the $R \& D$ subsample, the observed variability in the estimated price-cost markup seems to be common to all firms while the true dispersion in $\hat{\phi}_{i}$ amounts to 0.200 .

\section{Conclusion}

This paper focuses on cross-sectional heterogeneity in price-cost margins and the extent of rent sharing among 48 sectors and 10738 (mainly manufacturing) firms in France. At the sectoral level, the average price-cost mark-up and the average extent of rent sharing are estimated at 1.701 and 0.368 respectively. Ignoring the occurence of rent sharing reduces the average price-cost mark-up to 1.500. At the firm level, we estimate the true dispersion or true heterogeneity in the parameters of interest using the Swamy (1970) methodology. The estimates of the firm-level average price-cost mark-up and extent of rent sharing amount to 1.814 and 0.558 respectively, while the corresponding estimates of their robust true dispersion are 0.694 and 0.204 , which seems plausible given our prior expectation about a reasonable heterogeneity in both parameters. Excluding the existence of rent sharing brings the firm-level average price-cost mark-up down to 1.491. The corresponding robust true dispersion amounts to 0.493 . 
Table A.1

Sector analysis: Sector repartition and estimated sector-level mark-up $\hat{\mu}_{j}$

\begin{tabular}{|c|c|c|c|c|c|c|c|}
\hline & & & & & & & $\mathrm{IM}$ \\
\hline & Code & Name & $\begin{array}{c}\text { \# Obs. } \\
\text { (\# Firms) }\end{array}$ & $\hat{\beta}_{j}$ & $\hat{\mu}_{j}=\frac{1}{1-\widehat{\beta}_{j}}$ & $\hat{\beta}_{j}$ & $\hat{\mu}_{j}=\frac{1}{1-\widehat{\beta}_{j}}$ \\
\hline Sec 1 & B01 & Meat preparations & $6848(458)$ & $0.330^{* * *}(0.013)$ & $1.493^{* * *}(0.030)$ & $0.326^{* * *}(0.050)$ & $1.483^{* * *}(0.111)$ \\
\hline Sec 2 & B02 & Milk products & $1781(114)$ & $0.246^{* * *}(0.020)$ & $1.327^{* * *}(0.036)$ & $0.279^{* * *}(0.070)$ & $1.387^{* * *}(0.135)$ \\
\hline Sec 3 & B03 & Beverages & $1739(108)$ & $0.383^{* * *}(0.024)$ & $1.620^{* * *}(0.063)$ & $0.310^{* * *}(0.052)$ & $1.450^{* * *}(0.109)$ \\
\hline $\operatorname{Sec} 4$ & B04 & Food production for animals & $1867(122)$ & $0.299^{* * *}(0.021)$ & $1.427^{* * *}(0.043)$ & $0.282^{* * *}(0.039)$ & $1.394^{* * *}(0.075)$ \\
\hline Sec 5 & B05 & Other food products & $8148(538)$ & $0.309^{* * *}(0.009)$ & $1.447^{* * *}(0.019)$ & $0.325^{* * *}(0.046)$ & $1.482^{* * *}(0.101)$ \\
\hline Sec 6 & C11 & Clothing and skin goods & $7717(499)$ & $0.349^{* * *}(0.009)$ & $1.538^{* * *}(0.022)$ & $0.320^{* * *}(0.037)$ & $1.471^{* * *}(0.082)$ \\
\hline $\operatorname{Sec} 8$ & $\mathrm{C} 20$ & Publishing, (re)printing & $11840(778)$ & $0.269^{* * *}(0.006)$ & $1.369^{* * *}(0.012)$ & $0.264^{* * *}(0.021)$ & $1.358^{* * *}(0.040)$ \\
\hline Sec 9 & C31 & Pharmaceutical products & $1441(87)$ & $0.411^{* * *}(0.020)$ & $1.699^{* * *}(0.059)$ & $0.360^{* * *}(0.054)$ & $1.562^{* * *}(0.133)$ \\
\hline Sec 10 & C32 & Soap, perfume and maintenance products & $1376(84)$ & $0.333^{* * *}(0.022)$ & $1.501^{* * *}(0.049)$ & $0.263^{* * *}(0.046)$ & $1.358^{* * *}(0.086)$ \\
\hline Sec 11 & $\mathrm{C} 41$ & Furniture & $4983(324)$ & $0.289^{* * *}(0.009)$ & $1.406^{* * *}(0.018)$ & $0.309^{* * *}(0.034)$ & $1.448^{* * *}(0.072)$ \\
\hline Sec 12 & $\mathrm{C} 42$ & Jewellery and musical instruments & $984(61)$ & $0.328^{* * *}(0.022)$ & $1.489^{* * *}(0.049)$ & $0.308^{* * *}(0.136)$ & $1.446^{* * *}(0.284)$ \\
\hline Sec 13 & $\mathrm{C} 43$ & Sport articles, games and other products & $2282(151)$ & $0.358^{* * *}(0.018)$ & $1.559^{* * *}(0.045)$ & $0.283^{* * *}(0.057)$ & $1.395^{* * *}(0.112)$ \\
\hline Sec 14 & $\mathrm{C} 46$ & Optical and photographic instruments, clockwork & $1126(73)$ & $0.371^{* * *}(0.021)$ & $1.590^{* * *}(0.053)$ & $0.252^{* * *}(0.075)$ & $1.337^{* * *}(0.134)$ \\
\hline Sec 15 & D01 & Motor vehicles & $2124(137)$ & $0.325^{* * *}(0.016)$ & $1.482^{* * *}(0.036)$ & $0.311^{* * *}(0.044)$ & $1.451^{* * *}(0.093)$ \\
\hline Sec 18 & E21 & Metal products for construction & $3275(219)$ & $0.283^{* * *}(0.015)$ & $1.394^{* * *}(0.030)$ & $0.209^{* * *}(0.038)$ & $1.265^{* * *}(0.062)$ \\
\hline Sec 19 & $\mathrm{E} 22$ & Ferruginous and steam boilers & $5965(399)$ & $0.329^{* * *}(0.013)$ & $1.492^{* * *}(0.029)$ & $0.331^{* * *}(0.039)$ & $1.496^{* * *}(0.087)$ \\
\hline Sec 20 & E23 & Mechanical equipment & $2527(157)$ & $0.354^{* * *}(0.019)$ & $1.549^{* * *}(0.046)$ & $0.368^{* * *}(0.054)$ & $1.583^{* * *}(0.136)$ \\
\hline Sec 21 & $\mathrm{E} 24$ & Machinery for general usage & $4524(296)$ & $0.354^{* * *}(0.013)$ & $1.548^{* * *}(0.033)$ & $0.287^{* * *}(0.043)$ & $1.404^{* * *}(0.086)$ \\
\hline Sec 22 & $\mathrm{E} 25-\mathrm{E} 26$ & Agriculture machinery & $1928(127)$ & $0.374^{* * *}(0.022)$ & $1.598^{* * *}(0.058)$ & $0.231^{* * *}(0.050)$ & $1.301^{* * *}(0.085)$ \\
\hline Sec 23 & $\mathrm{E} 27$ & Other machinery for specific usage & $4302(285)$ & $0.383^{* * *}(0.014)$ & $1.622^{* * *}(0.037)$ & $0.352^{* * *}(0.059)$ & $1.545^{* * *}(0.142)$ \\
\hline Sec 24 & E31-E32 & Office and electronic machinery & $1220(79)$ & $0.316^{* * *}(0.023)$ & $1.463^{* * *}(0.049)$ & $0.317^{* * *}(0.090)$ & $1.465^{* * *}(0.193)$ \\
\hline Sec 25 & E33 & Emission and transmission equipment & $905(61)$ & $0.291^{* * *}(0.030)$ & $1.411^{* * *}(0.061)$ & $0.294^{* * *}(0.133)$ & $1.417^{* * *}(0.268)$ \\
\hline Sec 26 & E34 & Orthopaedic equipment & $1156(76)$ & $0.285^{* * *}(0.025)$ & $1.399^{* * *}(0.049)$ & $0.364^{* * *}(0.086)$ & $1.574^{* * *}(0.214)$ \\
\hline Sec 27 & E35 & Precision instruments & $1807(122)$ & $0.345^{* * *}(0.023)$ & $1.528^{* * *}(0.055)$ & $0.321^{* * *}(0.067)$ & $1.474^{* * *}(0.146)$ \\
\hline Sec 28 & F11-F12 & Mineral products & $3043(202)$ & $0.368^{* * *}(0.014)$ & $1.582^{* * *}(0.035)$ & $0.326^{* * *}(0.048)$ & $1.485^{* * *}(0.107)$ \\
\hline Sec 29 & F13 & Glass products & $1458(92)$ & $0.361^{* * *}(0.025)$ & $1.565^{* * *}(0.062)$ & $0.299^{* * *}(0.066)$ & $1.426^{* * *}(0.134)$ \\
\hline
\end{tabular}


Table A.1 (ctd)

Sector analysis: Sector repartition and estimated sector-level mark-up $\hat{\mu}_{j}$

\begin{tabular}{|c|c|c|c|c|c|c|c|}
\hline & & & & \multicolumn{2}{|c|}{ OLS } & \multicolumn{2}{|c|}{ GMM } \\
\hline & Code & Name & $\begin{array}{c}\text { \# Obs. } \\
\text { (\# Firms) }\end{array}$ & $\hat{\beta}_{j}$ & $\hat{\mu}_{j}=\frac{1}{1-\widehat{\beta}_{j}}$ & $\hat{\beta}_{j}$ & $\hat{\mu}_{j}=\frac{1}{1-\widehat{\beta}_{j}}$ \\
\hline Sec 30 & F14 & Earthenware products and construction material & $5986(387)$ & $0.398^{* * *}(0.015)$ & $1.663^{* * *}(0.043)$ & $0.379^{* * *}(0.053)$ & $1.610^{* * *}(0.139)$ \\
\hline Sec 31 & $\mathrm{~F} 21$ & Textile art & $4467(280)$ & $0.320^{* * *}(0.011)$ & $1.471^{* * *}(0.024)$ & $0.326^{* * *}(0.033)$ & $1.484^{* * *}(0.074)$ \\
\hline Sec 32 & $\mathrm{~F} 22$ & Textile products & $3489(224)$ & $0.322^{* * *}(0.013)$ & $1.475^{* * *}(0.029)$ & $0.332^{* * *}(0.039)$ & $1.498^{* * *}(0.087)$ \\
\hline Sec 33 & F 23 & Clothing & $1471(93)$ & $0.313^{* * *}(0.021)$ & $1.456^{* * *}(0.044)$ & $0.314^{* * *}(0.041)$ & $1.459^{* * *}(0.087)$ \\
\hline Sec 34 & F31 & Wooden products & $7559(495)$ & $0.321^{* * *}(0.007)$ & $1.473^{* * *}(0.017)$ & $0.321^{* * *}(0.042)$ & $1.474^{* * *}(0.091)$ \\
\hline Sec 35 & F32-F33 & Paper and printing products & $4925(306)$ & $0.320^{* * *}(0.009)$ & $1.472^{* * *}(0.019)$ & $0.311^{* * *}(0.029)$ & $1.452^{* * *}(0.062)$ \\
\hline Sec 36 & F41-F42 & Mineral and organic chemical products & $1166(73)$ & $0.361^{* * *}(0.021)$ & $1.565^{* * *}(0.052)$ & $0.372^{* * *}(0.066)$ & $1.594^{* * *}(0.168)$ \\
\hline Sec 37 & F43 & Parachemical products & $1736(110)$ & $0.351^{* * *}(0.018)$ & $1.541^{* * *}(0.044)$ & $0.398^{* * *}(0.056)$ & $1.661^{* * *}(0.157)$ \\
\hline Sec 38 & F45 & Rubber products & $1083(70)$ & $0.346^{* * *}(0.028)$ & $1.530^{* * *}(0.067)$ & $0.415^{* * *}(0.080)$ & $1.711^{* * *}(0.236)$ \\
\hline Sec 39 & F46 & Transformation of plastic products & $8323(552)$ & $0.283^{* * *}(0.007)$ & $1.396^{* * *}(0.014)$ & $0.270^{* * *}(0.040)$ & $1.370^{* * *}(0.076)$ \\
\hline $\operatorname{Sec} 40$ & F51-F52 & Steel products, non-ferrous metals & $1735(108)$ & $0.357^{* * *}(0.021)$ & $1.555^{* * *}(0.052)$ & $0.387^{* * *}(0.049)$ & $1.632^{* * *}(0.132)$ \\
\hline $\operatorname{Sec} 41$ & F53 & Ironware & $1853(115)$ & $0.311^{* * *}(0.014)$ & $1.451^{* * *}(0.030)$ & $0.313^{* * *}(0.031)$ & $1.455^{* * *}(0.067)$ \\
\hline Sec 42 & F54 & Industrial service to metal products & $14937(991)$ & $0.335^{* * *}(0.006)$ & $1.504^{* * *}(0.013)$ & $0.371^{* * *}(0.040)$ & $1.590^{* * *}(0.103)$ \\
\hline Sec 43 & F55 & Metal products & $7603(487)$ & $0.362^{* * *}(0.010)$ & $1.567^{* * *}(0.026)$ & $0.375^{* * *}(0.045)$ & $1.600^{* * *}(0.117)$ \\
\hline $\operatorname{Sec} 44$ & F56 & Recuperation & $1178(80)$ & $0.567^{* * *}(0.033)$ & $2.314^{* * *}(0.179)$ & $0.481^{* * *}(0.065)$ & $1.930^{* * *}(0.242)$ \\
\hline Sec 45 & F61 & Electrical goods & $3295(206)$ & $0.337^{* * *}(0.019)$ & $1.508^{* * *}(0.044)$ & $0.313^{* * *}(0.042)$ & $1.455^{* * *}(0.089)$ \\
\hline $\operatorname{Sec} 46$ & F62 & Electrical components & $1361(91)$ & $0.344^{* * *}(0.025)$ & $1.525^{* * *}(0.060)$ & $0.341^{* * *}(0.060)$ & $1.519^{* * *}(0.140)$ \\
\hline $\operatorname{Sec} 47$ & F62 & Energy & $1304(87)$ & $0.429^{* * *}(0.026)$ & $1.754^{* * *}(0.081)$ & $0.448^{* * *}(0.058)$ & $1.811^{* * *}(0.190)$ \\
\hline $\operatorname{Sec} 48$ & G11-G15, G21-G22 & Construction & $1165(80)$ & $0.377^{* * *}(0.040)$ & $1.606^{* * *}(0.103)$ & $0.413^{* * *}(0.078)$ & $1.705^{* * *}(0.227)$ \\
\hline \multicolumn{4}{|c|}{ Sector average (median) } & $0.343(0.340)$ & $1.533(1.517)$ & $0.329(0.320)$ & $1.500(1.472)$ \\
\hline \multicolumn{3}{|c|}{ Overall average (Sd.) } & $145552(10738)$ & $0.360^{* * *}(0.002)$ & $1.563^{* * *}(0.005)$ & $0.231^{* * *}(0.024)$ & $1.301^{* * *}(0.041)$ \\
\hline
\end{tabular}

$S R_{i t}=\Delta q_{i t}-\left(\frac{1}{n_{t}} \sum_{t=1}^{n_{t}} \alpha_{N_{i t}}\right) \Delta n_{i t}-\left(\frac{1}{n_{t}} \sum_{t=1}^{n_{t}} \alpha_{M_{i t}}\right) \Delta m_{i t}-\left(1-\frac{1}{n_{t}} \sum_{t=1}^{n_{t}} \alpha_{N_{i t}}-\frac{1}{n_{t}} \sum_{t=1}^{n_{t}} \alpha_{M_{i t}}\right) \Delta k_{i t}$

$$
=\beta\left(\Delta q_{i t}-\Delta k_{i t}\right)+(1-\beta) \zeta_{i t}
$$

Manufacturing industry (Sec 1-Sec 46), Energy (Sec 47) and Construction (Sec 48).

Time dummies are included but not reported.

Robust standard errors in parentheses. ${ }^{* *}$ Significant at $1 \%$; ${ }^{* *}$ Significant at $5 \%$; * Significant at $10 \%$.

Instruments GMM: $\Delta n, \Delta m$ and $\Delta k$, dated $(t-2)$ and $(t-3)$ [sectoral results]; $(t-3)$ and $(t-4)$ [overall result]. 
Table A.2

Heterogeneity of firm-level mark-up $\widehat{\mu}_{i}$ :

Different indicators and estimates: Full sample (10738 firms)

\begin{tabular}{|c|c|c|c|c|}
\hline \multirow[t]{2}{*}{ Full sample (10738 firms) } & \multicolumn{2}{|c|}{ OLS } & \multicolumn{2}{|c|}{ TSLS } \\
\hline & & $\hat{\mu}_{i}=\frac{1}{1-\widehat{\beta}_{i}}$ & $\hat{\beta}_{i}$ & $\hat{\mu}_{i}=\frac{1}{1-\widehat{\beta}_{i}}$ \\
\hline Simple average & 0.339 & 1.626 & 0.343 & 1.491 \\
\hline Weighted average & 0.310 & 1.331 & 0.319 & 1.237 \\
\hline Median & 0.313 & 1.444 & 0.314 & 1.370 \\
\hline Observed variance $\operatorname{sd}_{o}^{2}\left(\right.$ disp. sd $\left._{o}\right)$ & $\begin{array}{c}0.062 \\
(0.249)\end{array}$ & $\begin{array}{l}1120.46 \\
(33.473)\end{array}$ & $\begin{array}{c}0.325 \\
(0.570)\end{array}$ & $\begin{array}{c}1998 \\
(44.698)\end{array}$ \\
\hline Robust observed variance $\mathbf{s d}_{r o}^{2}\left(\right.$ disp. $\left.\mathbf{s d}_{r_{O}}\right)$ & $\begin{array}{c}0.046 \\
(0.215) \\
\end{array}$ & $\begin{array}{c}0.229 \\
(0.479) \\
\end{array}$ & $\begin{array}{c}0.108 \\
(0.329)\end{array}$ & $\begin{array}{c}0.442 \\
(0.664) \\
\end{array}$ \\
\hline Sampling variance $\mathrm{sd}_{s}^{2}\left(\right.$ disp. $\left.\mathrm{sd}_{s}\right)$ & $\begin{array}{c}0.029 \\
(0.170)\end{array}$ & $\begin{array}{c}7.96 \mathrm{e}+8 \\
(28213)\end{array}$ & $\begin{array}{c}1.146 \\
(1.070)\end{array}$ & $\begin{array}{c}3.64 \mathrm{e}+9 \\
(60332)\end{array}$ \\
\hline Robust sampling variance $\mathbf{s d}_{r s}^{2}\left(\right.$ disp. $\left.\mathbf{s d}_{r s}\right)$ & $\begin{array}{c}0.009 \\
(0.094) \\
\end{array}$ & $\begin{array}{c}0.049 \\
(0.221) \\
\end{array}$ & $\begin{array}{c}0.045 \\
(0.212) \\
\end{array}$ & $\begin{array}{c}0.198 \\
(0.444) \\
\end{array}$ \\
\hline True variance $\sigma_{t}^{2}\left(\text { disp. } \sigma_{t}\right)^{a}$ & $\begin{array}{c}0.033 \\
(0.181)\end{array}$ & 0 & 0 & 0 \\
\hline Robust true variance $\boldsymbol{\sigma}_{r t}^{2}\left(\text { disp. } \boldsymbol{\sigma}_{r t}\right)^{a}$ & $\begin{array}{c}0.037 \\
(0.192) \\
\end{array}$ & $\begin{array}{c}0.180 \\
(0.424) \\
\end{array}$ & $\begin{array}{c}0.063 \\
(0.250) \\
\end{array}$ & $\begin{array}{c}0.244 \\
(0.493)\end{array}$ \\
\hline F-test $^{b}$ & 2.137 & $1.407 \mathrm{e}-6$ & 0.283 & $5.489 \mathrm{e}-7$ \\
\hline F-test ${ }^{b}$ & 5.111 & 4.673 & 2.400 & 2.232 \\
\hline
\end{tabular}

Instruments TSLS: 2-period lagged values of $\Delta n, \Delta m$ and $\Delta k$.

${ }^{a}$ (Robust) true variance is computed by adjusting the (robust) observed variance for (robust) sampling variability: $\sigma_{(r) t}^{2}=s d_{(r) o}^{2}-s d_{(r) s}^{2}$.

${ }^{b}$ F-test $=\frac{s d_{(r) o}^{2}}{s d_{(r) s}^{2}}$. 


\section{References}

[1] Bughin, J., 1996, Trade Unions and Firms' Product Market Power, The Journal of Industrial Economics, XLIV(3), 289-307.

[2] Crépon, B., R. Desplatz and J. Mairesse, 1999, Estimating Price-Cost Margins, Scale Economies and Workers' Bargaining Power at the Firm Level, CREST Working Paper G9917, Centre de Recherche en Economie et Statistique.

[3] Crépon, B., R. Desplatz and J. Mairesse, 2002, Price-Cost Margins and Rent Sharing: Evidence from a Panel of French Manufacturing Firms, Centre de Recherche en Economie et Statistique, revised version.

[4] Dobbelaere, S., 2004, Estimation of Price-Cost Margins and Union Bargaining Power for Belgian Manufacturing, International Journal of Industrial Organization, 22(10), 1381-1398.

[5] Doornik, J.A., M. Arellano and S. Bond, 2002, Panel Data Estimation using DPD for Ox, Nuffield College, Oxford.

[6] Hall, R.E., 1988, The Relationship between Price and Marginal Cost in US Industry, Journal of Political Economy, 96, 921-947.

[7] Leamer, E.E., 1978, Specification Searches: Ad hoc Inference with Nonexperimental Data, New York: John Wiley and Sons.

[8] Mairesse J. and Z. Griliches, 1990, Heterogeneity in Panel Data: Are there Stable Production Functions?, in: Champsaur, P., Deleau, M., Grandmont, J.M., Laroque, G., Guesnerie, R., Henry, C., Laffont, J.J., Mairesse, J., Monfort, A., Younes, Y. (Eds.), Essays in Honor of Edmond Malinvaud, vol. 3, Cambridge, MA: MIT Press.

[9] Neven, D.J., L. Röller and Z. Zhang, 2002, Endogenous Costs and PriceCosts Margins, DIW Berlin Discussion Paper 294, German Institute for Economic Research, Berlin.

[10] Swamy, P.A.V.B., 1970, Efficient Inference in a Random Coefficient Model, Econometrica, 38, 311-323.

[11] Woolridge, J., 2002, Econometric Analysis of Cross sections and Panel Data, Cambridge, MA: MIT Press. 
Table 1

Summary statistics

\begin{tabular}{lccccc}
\hline Variables & \multicolumn{5}{c}{$1978-2001$} \\
\hline & Mean & Sd. & $\mathrm{Q}_{1}$ & $\mathrm{Q}_{3}$ & $\mathrm{~N}$ \\
\hline Real firm output growth rate $\Delta q$ & 0.023 & 0.286 & -0.066 & 0.110 & 168113 \\
Labour growth rate $\Delta n$ & 0.006 & 0.237 & -0.046 & 0.060 & 168113 \\
Capital growth rate $\Delta k$ & -0.003 & 0.318 & -0.077 & 0.063 & 168113 \\
Materials growth rate $\Delta m$ & 0.045 & 0.394 & -0.069 & 0.151 & 167934 \\
Labour share in nominal output $\alpha_{N}$ & 0.314 & 0.143 & 0.210 & 0.398 & 168113 \\
Materials share in nominal output $\alpha_{M}$ & 0.497 & 0.174 & 0.389 & 0.616 & 168113 \\
Solow residual $S R^{a}$ & -0.0003 & 0.144 & -0.059 & 0.059 & 167934 \\
$\Delta q-\Delta k$ & 0.026 & 0.258 & -0.086 & 0.136 & 168113 \\
$\left(\alpha_{N}+\alpha_{M}-1\right)(\Delta n-\Delta k)$ & -0.001 & 0.059 & -0.001 & 0.010 & 168113 \\
\hline${ }^{a} R=\Delta q-\alpha_{N} \Delta n-\alpha_{M} \Delta m-\left(1-\alpha_{N}-\alpha_{M}\right) \Delta k$. & & &
\end{tabular}


Table 2

Sector analysis: Estimated sector-level mark-up $\hat{\mu}_{j}$ and extent of rent sharing $\hat{\phi}_{j}$

\begin{tabular}{|c|c|c|c|c|c|c|c|c|c|}
\hline & & & & LS & & & & $\mathrm{IM}$ & \\
\hline & Code & $\hat{\beta}_{j}$ & $\hat{\mu}_{j}=\frac{1}{1-\widehat{\beta}_{j}}$ & $\widehat{\gamma}_{j}$ & $\hat{\phi}_{j}=\frac{\hat{\gamma}_{j}}{1+\hat{\gamma}_{j}}$ & $\hat{\beta}_{j}$ & $\hat{\mu}_{j}=\frac{1}{1-\widehat{\beta}_{j}}$ & $\widehat{\gamma}_{j}$ & $\hat{\phi}_{j}=\frac{\hat{\gamma}_{j}}{1+\hat{\gamma}_{j}}$ \\
\hline Sec 1 & B01 & $0.317^{* * *}(0.014)$ & $1.464^{* * *}(0.030)$ & $-0.081^{* * *}(0.033)$ & $-0.088^{* * *}(0.039)$ & $0.303^{* * *}(0.059)$ & $1.435^{* * *}(0.122)$ & $-0.145(0.163)$ & $-0.170(0.223)$ \\
\hline Sec 2 & B02 & $242^{* * *}(0.021)$ & $1.320^{* * *}(0.036)$ & $-0.040(0.121)$ & $-0.041(0.131)$ & $.296^{* * *}(0.079)$ & $1.420^{* * *}(0.160)$ & $0.113(0.295)$ & $0.101(0.238)$ \\
\hline Sec 3 & B03 & $433^{* * *}(0.028)$ & $1.764^{* * *}(0.087)$ & $0.515^{* * *}(0.107)$ & $0.340^{* * *}(0.046)$ & $0.359^{* * *}(0.064)$ & $1.562^{* * *}(0.158)$ & $0.604^{* *}(0.298)$ & $0.376^{* * *}(0.115)$ \\
\hline $\operatorname{Sec} 4$ & B04 & $307^{* * *}(0.022)$ & $1.444^{* * *}(0.047)$ & $0.068(0.076)$ & $0.064(0.066)$ & $.282^{* * *}(0.045)$ & $1.393^{* * *}(0.088)$ & $-0.005(0.284)$ & $-0.005(0.287)$ \\
\hline Sec 5 & B05 & $392^{* * *}(0.011)$ & $1.644^{* * *}(0.030)$ & $0.721^{* * *}(0.068)$ & $0.419^{* * *}(0.023)$ & $.416^{* * *}(0.046)$ & $1.713^{* * *}(0.135)$ & $0.650^{* * *}(0.176)$ & $0.394^{* * *}(0.064)$ \\
\hline $\operatorname{Sec} 6$ & C11 & $0.459^{* * *}(0.011)$ & $1.850^{* * *}(0.040)$ & $1.170^{* * *}(0.106)$ & $0.539^{* * *}(0.022)$ & $.413^{* * *}(0.043)$ & $1.703^{* * *}(0.126)$ & $0.902^{* * *}(0.267)$ & $0.474^{* * *}(0.074)$ \\
\hline Sec 7 & $\mathrm{C} 12$ & $0.452^{* * *}(0.016)$ & $1.825^{* * *}(0.056)$ & $0.944^{* * *}(0.109)$ & $0.485^{* * *}(0.029)$ & $0.402^{* * *}(0.063)$ & $1.673^{* * *}(0.178)$ & $0.725^{* * *}(0.262)$ & $0.420^{* * *}(0.088)$ \\
\hline $\operatorname{Sec} 8$ & $\mathrm{C} 20$ & $342^{* * *}(0.032)$ & $1.522^{* * *}(0.075)$ & $0.627^{* * *}(0.265)$ & $0.385^{* * *}(0.100)$ & $0.374^{* * *}(0.0$ & $1.598^{* * *}(0.141)$ & $0.621^{* *}(0.3$ & $0.383^{* * *}(0.117)$ \\
\hline Sec 9 & C31 & $0.527^{* * *}(0.029)$ & $2.115^{* * *}(0.131)$ & $0.891^{* * *}(0.137)$ & $0.471^{* * *}(0.038)$ & $.427^{* * *}(0.077)$ & $1.747^{* * *}(0.235)$ & $0.504(0.408)$ & $0.335^{* * *}(0.180)$ \\
\hline Sec 10 & $\mathrm{C} 32$ & $0.399^{* * *}(0.024)$ & $1.663^{* * *}(0.067)$ & $0.492^{* * *}(0.127)$ & $0.330^{* * *}(0.057)$ & $0.381^{* * *}(0.056)$ & $1.615^{* * *}(0.147)$ & $0.721^{* * *}(0.172)$ & $0.419^{* * *}(0.058)$ \\
\hline Sec 11 & C41 & $0.383^{* * *}(0.010)$ & $1.621^{* * *}(0.027)$ & $1.117^{* * *}(0.108)$ & $0.527^{* * *}(0.024)$ & $.392^{* * *}(0.036)$ & $1.646^{* * *}(0.098)$ & $0.898^{* * *}(0$ & $0.473^{* * *}(0.066)$ \\
\hline Sec 12 & $\mathrm{C} 42$ & $0.459^{* * *}(0.023)$ & $1.849^{* * *}(0.079)$ & $1.400^{* * *}(0.195)$ & $0.583^{* * *}(0.033)$ & $0.448^{* * *}(0.095)$ & $1.812^{* * *}(0.312)$ & $1.592^{* * *}(0.5$ & $0.614^{* * *}(0.088)$ \\
\hline Sec 13 & $\mathrm{C} 43$ & $0.440^{* * *}(0.020)$ & $1.786^{* * *}(0.066)$ & $0.677^{* * *}(0.105)$ & $0.403^{* * *}(0.037)$ & $0.427^{* * *}(0.053)$ & $1.747^{* * *}(0.164)$ & $0.764^{* * *}(0.228)$ & $0.433^{* * *}(0.073)$ \\
\hline Sec 14 & $\mathrm{C} 46$ & $0.458^{* * *}(0.024)$ & $1.846^{* * *}(0.082)$ & $0.821^{* * *}(0.218)$ & $0.450^{* * *}(0.065)$ & $.414^{* * *}(0.077)$ & $1.706^{* * *}(0.226)$ & $1.297^{* * *}(0$. & $0.564^{* * *}(0.092)$ \\
\hline Sec 15 & D01 & $0.358^{* * *}(0.018)$ & $1.559^{* * *}(0.045)$ & $0.327^{* * *}(0.101)$ & $0.246^{* * *}(0.057)$ & $0.337^{* * *}(0.052)$ & $1.508^{* * *}(0.119)$ & $0.219(0.24$ & $0.180(0.167)$ \\
\hline Sec 16 & D02 & $0.388^{* * *}(0.021)$ & $1.636^{* * *}(0.056)$ & $0.609^{* * *}(0.153)$ & $0.378^{* * *}(0.059)$ & $0.441^{* * *}(0.066)$ & $1.789^{* * *}(0.212)$ & $0.439(0.313)$ & $0.305^{* * *}(0.151)$ \\
\hline Sec 17 & E11-E14 & $0.456^{* * *}(0.025)$ & $1.841^{* * *}(0.087)$ & $1.229^{* * *}(0.295)$ & $0.551^{* * *}(0.059)$ & $0.381^{* * *}(0.074)$ & $1.617^{\text {*** }}(0.194)$ & $1.309^{* * *}(0$. & $0.567^{* * *}(0.097)$ \\
\hline Sec 18 & E21 & $0.331^{* * *}(0.019)$ & $1.495^{* * *}(0.043)$ & $1.039^{* * *}(0.311)$ & $0.509^{* * *}(0.074)$ & $0.274^{* * *}(0.044)$ & $1.378^{* * *}(0.084)$ & $1.229^{*}(0.770)$ & $0.551^{* * *}(0.156)$ \\
\hline Sec 19 & E22 & $0.407^{* * *}(0.017)$ & $1.686^{* * *}(0.050)$ & $1.781^{* * *}(0.396)$ & $0.640^{* * *}(0.051)$ & $0.492^{* * *}(0.042)$ & $1.971^{* * *}(0.164)$ & $2.936^{* * *}(0.559)$ & $0.745^{* * *}(0.036)$ \\
\hline Sec 20 & E23 & $0.399^{* * *}(0.022)$ & $1.665^{* * *}(0.062)$ & $0.435^{* * *}(0.111)$ & $0.303^{* * *}(0.053)$ & $0.446^{* * *}(0.068)$ & $1.807^{* * *}(0.223)$ & $0.737^{* *}(0.325)$ & $0.424^{* * *}(0.108)$ \\
\hline Sec 21 & E24 & $0.386^{* * *}(0.015)$ & $1.631^{* * *}(0.040)$ & $0.437^{* * *}(0.122)$ & $0.304^{* * *}(0.059)$ & $0.318^{* * *}(0.055)$ & $1.467^{* * *}(0.119)$ & $0.408(0.34$ & $0.289^{*}(0.176)$ \\
\hline Sec 22 & E25-E26 & $0.427^{* * *}(0.024)$ & $1.747^{* * *}(0.073)$ & $0.845^{* * *}(0.176)$ & $0.458^{* * *}(0.051)$ & $0.292^{\text {*** }}(0.068)$ & $1.413^{* * *}(0.136)$ & $0.582(0.491)$ & $0.368(0.196)$ \\
\hline Sec 23 & E27 & $0.460^{* * *}(0.018)$ & $1.853^{* * *}(0.063)$ & $1.536^{* * *}(0.337)$ & $0.605^{* * *}(0.052)$ & $0.446^{* * *}(0.063)$ & $1.807^{* * *}(0.208)$ & $1.285^{* *}(0.619)$ & $0.562^{* * *}(0.118)$ \\
\hline Sec 24 & E31-E32 & $0.335^{* * *}(0.026)$ & $1.503^{* * *}(0.059)$ & $0.455^{* * *}(0.190)$ & $0.312^{\text {*** }}(0.089)$ & $0.343^{* * *}(0.097)$ & $1.522^{* * *}(0.226)$ & $0.631^{*}(0.384)$ & $0.387^{* * *}(0.144)$ \\
\hline Sec 25 & E33 & $0.281^{* * *}(0.032)$ & $1.392^{* * *}(0.062)$ & $-0.316(0.225)$ & $-0.462(0.481)$ & $0.242^{* *} \quad(0.112)$ & $1.319^{* * *}(0.195)$ & $0.071(0.787)$ & $0.066(0.686)$ \\
\hline Sec 26 & E34 & $0.358^{* * *}(0.036)$ & $1.557^{* * *}(0.087)$ & $0.868^{* * *}(0.235)$ & $0.464^{* * *}(0.067)$ & $0.440^{* * *}(0.101)$ & $1.788^{* * *}(0.325)$ & $0.930^{*}(0.499)$ & $0.482^{* * *}(0.134)$ \\
\hline Sec 27 & E35 & $0.366^{* * *}(0.026)$ & $1.577^{* * *}(0.067)$ & $0.562^{* * *}(0.231)$ & $0.359^{* * *}(0.094)$ & $0.351^{* * *}(0.059)$ & $1.541^{* * *}(0.141)$ & $1.387^{*}(0.796)$ & $0.581^{* * *}(0.139)$ \\
\hline Sec 28 & F11-F12 & $0.462^{* * *}(0.017)$ & $1.859^{* * *}(0.060)$ & $0.868^{* * *}(0.077)$ & $0.464^{* * *}(0.022)$ & $0.425^{* * *}(0.054)$ & $1.740^{* * *}(0.164)$ & $0.832^{* * *}(0.287)$ & $0.454^{* * *}(0.085)$ \\
\hline Sec 29 & F13 & $0.450^{* * *}(0.032)$ & $1.820^{* * *}(0.108)$ & $0.766^{* * *}(0.141)$ & $0.433^{* * *}(0.045)$ & $0.398^{* * *}(0.070)$ & $1.663^{* * *}(0.193)$ & $0.873^{* * *}(0.340)$ & $0.466^{* * *}(0.096)$ \\
\hline
\end{tabular}


Table 2 (ctd)

Sector analysis: Estimated sector-level mark-up $\hat{\mu}_{j}$ and extent of rent sharing $\hat{\phi}_{j}$

\begin{tabular}{|c|c|c|c|c|c|c|c|c|c|}
\hline & \multirow[b]{2}{*}{ Code } & \multicolumn{4}{|c|}{ OLS } & \multicolumn{4}{|c|}{ GMM } \\
\hline & & $\hat{\beta}_{j}$ & $\hat{\mu}_{j}=\frac{1}{1-\widehat{\beta}_{j}}$ & $\widehat{\gamma}_{j}$ & $\hat{\phi}_{j}=\frac{\hat{\gamma}_{j}}{1+\hat{\gamma}_{j}}$ & $\hat{\beta}_{j}$ & $\hat{\mu}_{j}=\frac{1}{1-\widehat{\beta}_{j}}$ & $\widehat{\gamma}_{j}$ & $\hat{\phi}_{j}=\frac{\hat{\gamma}_{j}}{1+\hat{\gamma}_{j}}$ \\
\hline Sec 30 & F14 & $0.477^{* * *}(0.019)$ & $1.912^{* * *}(0.069)$ & $0.611^{* * *}(0.076)$ & $0.379^{* * *}(0.029)$ & $0.454^{* * *}(0.057)$ & $1.834^{* * *}(0.193)$ & $0.524^{* * *}(0.215)$ & $0.343^{* * *}(0.092)$ \\
\hline Sec 31 & F21 & $0.391^{* * *}(0.013)$ & $1.642^{* * *}(0.037)$ & $0.867^{* * *}(0.114)$ & $0.464^{* * *}(0.032)$ & $0.399^{* * *}(0.044)$ & $1.666^{* * *}(0.124)$ & $0.590^{* * *}(0.209)$ & $0.371^{* * *}(0.082)$ \\
\hline Sec 32 & $\mathrm{~F} 22$ & $0.391^{* * *}(0.016)$ & $1.643^{* * *}(0.045)$ & $0.716^{* * *}(0.120)$ & $0.417^{* * *}(0.040)$ & $0.384^{* * *}(0.053)$ & $1.624^{* * *}(0.139)$ & $0.400^{*}(0.240)$ & $0.286^{* * *}(0.122)$ \\
\hline Sec 33 & F23 & $0.396^{* * *}(0.028)$ & $1.658^{* * *}(0.078)$ & $0.936^{* * *}(0.255)$ & $0.483^{* * *}(0.068)$ & $0.411^{* * *}(0.059)$ & $1.699^{* * *}(0.173)$ & $1.205^{* * *}(0.423)$ & $0.546^{* * *}(0.087)$ \\
\hline Sec 34 & F31 & $0.413^{* * *}(0.009)$ & $1.704^{* * *}(0.027)$ & $0.771^{* * *}(0.062)$ & $0.435^{* * *}(0.019)$ & $0.416^{* * *}(0.036)$ & $1.713^{* * *}(0.106)$ & $0.741^{* * *}(0.175)$ & $0.425^{* * *}(0.057)$ \\
\hline Sec 35 & F32-F33 & $0.415^{* * *}(0.012)$ & $1.711^{* * *}(0.037)$ & $0.659^{* * *}(0.075)$ & $0.397^{* * *}(0.027)$ & $0.356^{* * *}(0.046)$ & $1.554^{* * *}(0.112)$ & $0.343^{*}(0.186)$ & $0.255^{* * *}(0.103)$ \\
\hline Sec 36 & F41-F42 & $0.382^{* * *}(0.024)$ & $1.620^{* * *}(0.064)$ & $0.196(0.130)$ & $0.164^{*}(0.090)$ & $0.457^{* * *}(0.087)$ & $1.842^{* * *}(0.296)$ & $0.645^{*}(0.400)$ & $0.392^{* * *}(0.151)$ \\
\hline Sec 37 & F43 & $0.407^{* * *}(0.020)$ & $1.688^{* * *}(0.057)$ & $0.412^{* * *}(0.119)$ & $0.292^{* * *}(0.059)$ & $0.386^{* * *}(0.056)$ & $1.629^{* * *}(0.149)$ & $-0.040(0.185)$ & $-0.042(0.201)$ \\
\hline Sec 38 & F 45 & $0.415^{* * *}(0.029)$ & $1.709^{* * *}(0.085)$ & $0.477^{* * *}(0.179)$ & $0.323^{* * *}(0.082)$ & $0.458^{* * *}(0.096)$ & $1.846^{* * *}(0.329)$ & $0.380(0.344)$ & $0.275(0.180)$ \\
\hline Sec 39 & F46 & $0.368^{* * *}(0.009)$ & $1.583^{* * *}(0.025)$ & $0.891^{* * *}(0.097)$ & $0.471^{* * *}(0.027)$ & $0.353^{* * *}(0.044)$ & $1.547^{* * *}(0.106)$ & $0.685^{* * *}(0.262)$ & $0.406^{* * *}(0.092)$ \\
\hline Sec 40 & F51-F52 & $0.407^{* * *}(0.026)$ & $1.687^{* * *}(0.074)$ & $0.529^{* * *}(0.139)$ & $0.346^{* * *}(0.059)$ & $0.456^{* * *}(0.048)$ & $1.841^{* * *}(0.165)$ & $0.532^{* *}(0.274)$ & $0.347^{* * *}(0.116)$ \\
\hline Sec 41 & F53 & $0.450^{* * *}(0.015)$ & $1.820^{* * *}(0.051)$ & $1.415^{* * *}(0.103)$ & $0.586^{* * *}(0.017)$ & $0.469^{* * *}(0.036)$ & $1.884^{* * *}(0.130)$ & $1.214^{* * *}(0.192)$ & $0.548^{* * *}(0.039)$ \\
\hline Sec 42 & F54 & $0.474^{* * *}(0.008)$ & $1.903^{* * *}(0.030)$ & $1.510^{* * *}(0.082)$ & $0.601^{* * *}(0.013)$ & $0.512^{* * *}(0.049)$ & $2.051^{* * *}(0.207)$ & $1.690^{* * *}(0.325)$ & $0.628^{* * *}(0.044)$ \\
\hline $\operatorname{Sec} 43$ & F55 & $0.488^{* * *}(0.013)$ & $1.954^{* * *}(0.050)$ & $0.961^{* * *}(0.081)$ & $0.490^{* * *}(0.021)$ & $0.525^{* * *}(0.058)$ & $2.106^{* * *}(0.257)$ & $1.020^{* * *}(0.245)$ & $0.505^{* * *}(0.060)$ \\
\hline Sec 44 & F56 & $0.607^{* * *}(0.038)$ & $2.547^{* * *}(0.248)$ & $0.268^{* * *}(0.056)$ & $0.211^{* * *}(0.035)$ & $0.563^{* * *}(0.083)$ & $2.289^{* * *}(0.439)$ & $0.371^{* *}(0.195)$ & $0.270^{* * *}(0.103)$ \\
\hline Sec 45 & F61 & $0.386^{* * *}(0.020)$ & $1.630^{* * *}(0.055)$ & $0.621^{* * *}(0.124)$ & $0.383^{* * *}(0.047)$ & $0.332^{* * *}(0.047)$ & $1.497^{* * *}(0.107)$ & $0.257(0.268)$ & $0.204(0.169)$ \\
\hline Sec 46 & F62 & $0.404^{* * *}(0.026)$ & $1.678^{* * *}(0.074)$ & $0.791^{* * *}(0.278)$ & $0.441^{* * *}(0.086)$ & $0.419^{* * *}(0.074)$ & $1.722^{* * *}(0.221)$ & $1.098^{* * *}(0.358)$ & $0.523^{* * *}(0.081)$ \\
\hline $\operatorname{Sec} 47$ & F62 & $0.475^{* * *}(0.030)$ & $1.907^{* * *}(0.112)$ & $0.532^{* * *}(0.135)$ & $0.347^{* * *}(0.057)$ & $0.561^{* * *}(0.057)$ & $2.280^{* * *}(0.299)$ & $1.130^{* * *}(0.356)$ & $0.530^{* * *}(0.078)$ \\
\hline $\operatorname{Sec} 48$ & G11-G15, G21-G22 & $0.430^{* * *}(0.043)$ & $1.757^{* * *}(0.133)$ & $0.797^{* * *}(0.185)$ & $0.443^{* * *}(0.057)$ & $0.480^{* * *}(0.079)$ & $1.924^{* * *}(0.295)$ & $0.894^{* * *}(0.356)$ & $0.472^{* * *}(0.099)$ \\
\hline \multicolumn{2}{|c|}{ Sector average (median) } & $0.409 \quad(0.407)$ & $1.714(1.687)$ & $0.723(0.718)$ & $0.377(0.418)$ & $0.403(0.412)$ & $1.701(1.701)$ & $0.766(0.703)$ & $0.386(0.412)$ \\
\hline \multicolumn{2}{|c|}{ Overall average (Sd.) } & $0.429^{* * *}(0.003)$ & $1.753^{* * *}(0.009)$ & $0.750^{* * *}(0.025)$ & $0.428^{* * *}(0.014)$ & $0.404^{* * *}(0.037)$ & $1.678^{* * *}(0.105)$ & $1.135^{* * *}(0.196)$ & $0.531^{* * *}(0.042)$ \\
\hline
\end{tabular}

$S R_{i t}=\Delta q_{i t}-\left(\frac{1}{n_{t}} \sum_{t=1}^{n_{t}} \alpha_{N_{i t}}\right) \Delta n_{i t}-\left(\frac{1}{n_{t}} \sum_{t=1}^{n_{t}} \alpha_{M_{i t}}\right) \Delta m_{i t}-\left(1-\frac{1}{n_{t}} \sum_{t=1}^{n_{t}} \alpha_{N_{i t}}-\frac{1}{n_{t}} \sum_{t=1}^{n_{t}} \alpha_{M_{i t}}\right) \Delta k_{i t}$

$$
=\beta\left(\Delta q_{i t}-\Delta k_{i t}\right)+\gamma\left(\frac{1}{n_{t}} \sum_{t=1}^{n_{t}} \alpha_{N_{i t}}+\frac{1}{n_{t}} \sum_{t=1}^{n_{t}} \alpha_{M_{i t}}-1\right)\left(\Delta n_{i t}-\Delta k_{i t}\right)+(1-\beta) \zeta_{i t}
$$

Manufacturing industry (Sec 1-Sec 46), Energy (Sec 47) and Construction (Sec 48).

Time dummies are included but not reported.

Robust standard errors in parentheses. ${ }^{* * *}$ Significant at $1 \%$; ${ }^{* *}$ Significant at 5\%; * Significant at $10 \%$.

Instruments GMM: $\Delta n, \Delta m$ and $\Delta k$, dated $(t-2)$ and $(t-3)$ [sectoral results]; $(t-3)$ and $(t-4)$ [overall result]. 
Table 3

Heterogeneity of firm-level mark-up $\widehat{\mu}_{i}$ and extent of rent sharing $\widehat{\phi}_{i}$ :

Different indicators and estimates: Full sample (10738 firms)

\begin{tabular}{|c|c|c|c|c|c|c|c|c|}
\hline \multirow[t]{2}{*}{ Full sample (10738 firms) } & \multicolumn{4}{|c|}{ OLS } & \multicolumn{4}{|c|}{ TSLS } \\
\hline & $\hat{\beta}_{i}$ & $\hat{\mu}_{i}=\frac{1}{1-\widehat{\beta}_{i}}$ & $\widehat{\gamma}_{i}$ & $\hat{\phi}_{i}=\frac{\hat{\gamma}_{i}}{1+\widehat{\gamma}_{i}}$ & $\hat{\beta}_{i}$ & $\hat{\mu}_{i}=\frac{1}{1-\widehat{\beta}_{i}}$ & $\widehat{\gamma}_{i}$ & $\hat{\phi}_{i}=\frac{\hat{\gamma}_{i}}{1+\widehat{\gamma}_{i}}$ \\
\hline Simple average & 0.535 & 3.009 & 2.251 & 0.435 & 0.528 & 1.814 & 0.434 & 0.558 \\
\hline Weighted average & 0.539 & 1.724 & 1.973 & 0.837 & 0.541 & 1.354 & 1.990 & 0.899 \\
\hline Median & 0.531 & 2.044 & 2.077 & 0.696 & 0.533 & 1.614 & 2.036 & 0.775 \\
\hline Observed variance $\operatorname{sd}_{o}^{2}\left(\right.$ disp. sd $\left._{o}\right)$ & $\begin{array}{c}0.085 \\
(0.293)\end{array}$ & $\begin{array}{l}1212.45 \\
(34.820)\end{array}$ & $\begin{array}{l}3205.77 \\
(56.619)\end{array}$ & $\begin{array}{l}328.134 \\
(18.114)\end{array}$ & $\begin{array}{c}2.316 \\
(1.521)\end{array}$ & $\begin{array}{l}1196.46 \\
(34.589)\end{array}$ & $\begin{array}{c}17285 \\
(131.473)\end{array}$ & $\begin{array}{l}403.041 \\
(20.075)\end{array}$ \\
\hline Robust observed variance $\mathbf{s d}_{r o}^{2}\left(\right.$ disp. $\left.\mathbf{s d}_{r o}\right)$ & $\begin{array}{c}0.062 \\
(0.249)\end{array}$ & $\begin{array}{c}1.361 \\
(1.167)\end{array}$ & $\begin{array}{c}4.532 \\
(2.129)\end{array}$ & $\begin{array}{c}0.042 \\
(0.207) \\
\end{array}$ & $\begin{array}{c}0.188 \\
(0.434)\end{array}$ & $\begin{array}{c}1.990 \\
(1.411)\end{array}$ & $\begin{array}{l}12.496 \\
(3.535)\end{array}$ & $\begin{array}{c}0.069 \\
(0.263) \\
\end{array}$ \\
\hline Sampling variance $\mathbf{s d}_{s}^{2}\left(\right.$ disp. $\left.\mathrm{sd}_{s}\right)$ & $\begin{array}{c}0.046 \\
(0.214)\end{array}$ & $\begin{array}{l}5.55 \mathrm{e}+8 \\
(23558)\end{array}$ & $\begin{array}{c}1133 \\
(33.660)\end{array}$ & $\begin{array}{c}2.86 \mathrm{e}+9 \\
(53478)\end{array}$ & $\begin{array}{l}3339.97 \\
(57.792)\end{array}$ & $\begin{array}{l}1.35 \mathrm{e}+8 \\
(11618)\end{array}$ & $\begin{array}{c}312106 \\
(558.664)\end{array}$ & $\begin{array}{c}7.66 \mathrm{e}+10 \\
(276767)\end{array}$ \\
\hline Robust sampling variance $\mathbf{s d}_{r s}^{2}\left(\right.$ disp. $\left.\mathbf{s d}_{r s}\right)$ & $\begin{array}{c}0.010 \\
(0.100) \\
\end{array}$ & $\begin{array}{c}0.227 \\
(0.476) \\
\end{array}$ & $\begin{array}{c}0.561 \\
(0.748) \\
\end{array}$ & $\begin{array}{c}0.004 \\
(0.063) \\
\end{array}$ & $\begin{array}{c}0.107 \\
(0.327) \\
\end{array}$ & $\begin{array}{c}1.508 \\
(1.228) \\
\end{array}$ & $\begin{array}{c}7.354 \\
(2.711) \\
\end{array}$ & $\begin{array}{c}0.027 \\
(0.164) \\
\end{array}$ \\
\hline True variance $\sigma_{t}^{2}\left(\text { disp. } \sigma_{t}\right)^{a}$ & $\begin{array}{c}0.039 \\
(0.197)\end{array}$ & 0 & $\begin{array}{l}2072.77 \\
(45.527)\end{array}$ & 0 & 0 & 0 & 0 & 0 \\
\hline Robust true variance $\sigma_{r t}^{2}\left(\text { disp. } \sigma_{r t}\right)^{a}$ & $\begin{array}{c}0.052 \\
(0.228)\end{array}$ & $\begin{array}{c}1.134 \\
(1.064)\end{array}$ & $\begin{array}{c}3.971 \\
(1.992)\end{array}$ & $\begin{array}{c}0.038 \\
(0.194)\end{array}$ & $\begin{array}{c}0.081 \\
(0.284)\end{array}$ & $\begin{array}{c}0.482 \\
(0.694)\end{array}$ & $\begin{array}{c}5.142 \\
(2.267)\end{array}$ & $\begin{array}{c}0.042 \\
(0.204)\end{array}$ \\
\hline F-test ${ }^{b}$ & 1.847 & $2.184 \mathrm{e}-6$ & 2.829 & $1.147 \mathrm{e}-9$ & $6.934 \mathrm{e}-4$ & $8.862 \mathrm{e}-6$ & $5.538 \mathrm{e}-2$ & $5.261 \mathrm{e}-9$ \\
\hline $\mathbf{F}$-test ${ }^{b}$ & 6.200 & 5.995 & 8.078 & 10.500 & 1.757 & 1.319 & 1.699 & 2.555 \\
\hline
\end{tabular}

$S R_{t}=\Delta q_{t}-\left(\frac{1}{n_{t}} \sum_{t=1}^{n_{t}} \alpha_{N_{t}}\right) \Delta n_{t}-\left(\frac{1}{n_{t}} \sum_{t=1}^{n_{t}} \alpha_{M_{t}}\right) \Delta m_{t}-\left(1-\frac{1}{n_{t}} \sum_{t=1}^{n_{t}} \alpha_{N_{t}}-\frac{1}{n_{t}} \sum_{t=1}^{n_{t}} \alpha_{M_{t}}\right) \Delta k$

$$
=\beta\left(\Delta q_{t}-\Delta k_{t}\right)+\gamma\left(\frac{1}{n_{t}} \sum_{t=1}^{n_{t}} \alpha_{N_{t}}+\frac{1}{n_{t}} \sum_{t=1}^{n_{t}} \alpha_{M_{t}}-1\right)\left(\Delta n_{t}-\Delta k_{t}\right)+(1-\beta) \varepsilon_{t}
$$

Instruments TSLS: 2-period lagged values of $\Delta n, \Delta m$ and $\Delta k$.

${ }^{a}$ (Robust) true variance is computed by adjusting the (robust) observed variance for (robust) sampling variability:

$\sigma_{(r) t}^{2}=s d_{(r) o}^{2}-s d_{(r) s}^{2}$

${ }^{b}$ F-test $=\frac{s d_{(r) o}^{2}}{s d_{(r) s}^{2}}$. 
Table 4

Heterogeneity of firm-level mark-up $\widehat{\mu}_{i}$ and, firm-level mark-up $\widehat{\mu}_{i}$ and extent of rent sharing $\widehat{\phi}_{i}$ :

Different indicators and estimates: Cleaned sample - TSLS results

\begin{tabular}{|c|c|c|c|c|c|c|}
\hline & \multicolumn{2}{|c|}{5365 firms $^{c}$} & \multicolumn{4}{|c|}{2328 firms $^{d}$} \\
\hline & $\hat{\beta}_{i}$ & $\hat{\mu}_{i}=\frac{1}{1-\widehat{\beta}_{i}}$ & $\hat{\beta}_{i}$ & $\hat{\mu}_{i}=\frac{1}{1-\widehat{\beta}_{i}}$ & $\widehat{\gamma}_{i}$ & $\hat{\phi}_{i}=\frac{\hat{\gamma}_{i}}{1+\widehat{\gamma}_{i}}$ \\
\hline Simple average & 0.116 & 1.208 & 0.448 & 1.654 & 1.393 & 0.805 \\
\hline Weighted average & 0.199 & 1.169 & 0.468 & 1.452 & 2.772 & 0.910 \\
\hline Median & 0.165 & 1.195 & 0.433 & 1.678 & 3.580 & 0.810 \\
\hline Observed variance $\mathbf{s d}_{o}^{2}\left(\right.$ disp. sd $\left._{o}\right)$ & $\begin{array}{c}0.301 \\
(0.548)\end{array}$ & $\begin{array}{c}0.120 \\
(0.347)\end{array}$ & $\begin{array}{l}4.176 \\
(2.043)\end{array}$ & $\begin{array}{c}0.825 \\
(0.908)\end{array}$ & $\begin{array}{c}18457 \\
(135.859)\end{array}$ & $\begin{array}{c}0.023 \\
(0.154)\end{array}$ \\
\hline Robust observed variance $\mathbf{s d}_{r o}^{2}\left(\right.$ disp. $\left.\mathbf{s d}_{r o}\right)$ & $\begin{array}{c}0.041 \\
(0.203)\end{array}$ & $\begin{array}{c}0.083 \\
(0.280)\end{array}$ & $\begin{array}{c}0.051 \\
(0.226)\end{array}$ & $\begin{array}{c}0.454 \\
(0.674)\end{array}$ & $\begin{array}{l}10.758 \\
(3.280)\end{array}$ & $\begin{array}{c}0.019 \\
(0.138)\end{array}$ \\
\hline Sampling variance $\mathbf{s d}_{s}^{2}\left(\right.$ disp. $\left.\mathbf{s d}_{s}\right)$ & $\begin{array}{c}0.896 \\
(0.946)\end{array}$ & $\begin{array}{l}0.066 \\
(0.256)\end{array}$ & $\begin{array}{l}210.658 \\
(14.514)\end{array}$ & $\begin{array}{c}0.417 \\
(0.645)\end{array}$ & $\begin{array}{c}30971 \\
(175.985)\end{array}$ & $\begin{array}{c}0.007 \\
(0.083)\end{array}$ \\
\hline Robust sampling variance $\mathbf{s d}_{r s}^{2}\left(\right.$ disp. $\left.\mathbf{s d}_{r s}\right)$ & $\begin{array}{c}0.020 \\
(0.141)\end{array}$ & $\begin{array}{c}0.051 \\
(0.225)\end{array}$ & $\begin{array}{c}0.027 \\
(0.164)\end{array}$ & $\begin{array}{c}0.272 \\
(0.521)\end{array}$ & $\begin{array}{c}3.127 \\
(1.768)\end{array}$ & $\begin{array}{c}0.004 \\
(0.063)\end{array}$ \\
\hline True variance $\sigma_{t}^{2}\left(\text { disp. } \sigma_{t}\right)^{a}$ & 0 & $\begin{array}{c}0.054 \\
(0.232)\end{array}$ & 0 & $\begin{array}{c}0.408 \\
(0.638)\end{array}$ & 0 & $\begin{array}{c}0.016 \\
(0.126)\end{array}$ \\
\hline Robust true variance $\sigma_{r t}^{2}\left(\text { disp. } \sigma_{r t}\right)^{a}$ & $\begin{array}{c}0.021 \\
(0.144)\end{array}$ & $\begin{array}{c}0.032 \\
(0.178)\end{array}$ & $\begin{array}{c}0.024 \\
(0.154)\end{array}$ & $\begin{array}{c}0.182 \\
(0.426)\end{array}$ & $\begin{array}{c}7.631 \\
(2.762)\end{array}$ & $\begin{array}{c}0.015 \\
(0.122)\end{array}$ \\
\hline F-test ${ }^{b}$ & 0.335 & 1.818 & 0.019 & 1.978 & 0.595 & 3.285 \\
\hline F-test ${ }^{b}$ & 2.050 & 1.627 & 1.888 & 1.669 & 3.440 & 4.750 \\
\hline
\end{tabular}

Instruments TSLS: 2-period lagged values of $\Delta n, \Delta m$ and $\Delta k$

${ }^{a}$ (Robust) true variance is computed by adjusting the (robust) observed variance for (robust) sampling variability:

$\sigma_{(r) t}^{2}=s d_{(r) o}^{2}-s d_{(r) s}^{2}$

${ }^{b}$ F-test $=\frac{s d_{(r) o}^{2}}{s d_{(r) s}^{2}}$.

${ }^{c} S R_{t}=\Delta q_{t}-\left(\frac{1}{n_{t}} \sum_{t=1}^{n_{t}} \alpha_{N_{t}}\right) \Delta n_{t}-\left(\frac{1}{n_{t}} \sum_{t=1}^{n_{t}} \alpha_{M_{t}}\right) \Delta m_{t}-\left(1-\frac{1}{n_{t}} \sum_{t=1}^{n_{t}} \alpha_{N_{t}}-\frac{1}{n_{t}} \sum_{t=1}^{n_{t}} \alpha_{M_{t}}\right) \Delta k_{t}$

$=\beta\left(\Delta q_{t}-\Delta k_{t}\right)+(1-\beta) \varepsilon_{t}$

${ }^{d} S R_{t}=\Delta q_{t}-\left(\frac{1}{n_{t}} \sum_{t=1}^{n_{t}} \alpha_{N_{t}}\right) \Delta n_{t}-\left(\frac{1}{n_{t}} \sum_{t=1}^{n_{t}} \alpha_{M_{t}}\right) \Delta m_{t}-\left(1-\frac{1}{n_{t}} \sum_{t=1}^{n_{t}} \alpha_{N_{t}}-\frac{1}{n_{t}} \sum_{t=1}^{n_{t}} \alpha_{M_{t}}\right) \Delta k_{t}$

$=\beta\left(\Delta q_{t}-\Delta k_{t}\right)+\gamma\left(\frac{1}{n_{t}} \sum_{t=1}^{n_{t}} \alpha_{N_{t}}+\frac{1}{n_{t}} \sum_{t=1}^{n_{t}} \alpha_{M_{t}}-1\right)\left(\Delta n_{t}-\Delta k_{t}\right)+(1-\beta) \varepsilon_{t}$ 